\section{Measurement of renal} function in patients with chronic kidney disease

\author{
Euan A. Sandilands, ${ }^{1}$ Neeraj Dhaun, ${ }^{2,3}$ James W. Dear ${ }^{1,2} \&$ \\ David J. Webb²
}

${ }^{1}$ National Poisons Information Service Edinburgh, Royal Infirmary of Edinburgh, Edinburgh, UK,

${ }^{2}$ Clinical Pharmacology Unit, University/British Heart Foundation Centre for Cardiovascular Science,

University of Edinburgh, The Queen's Medical Research Institute, Edinburgh, UK and ${ }^{3}$ Department of

Renal Medicine, Royal Infirmary of Edinburgh, Edinburgh, UK

\section{Correspondence}

Dr Euan Sandilands BSc MRCP (UK), NPIS Edinburgh, Royal Infirmary of Edinburgh, 51 Little France Crescent, Edinburgh EH16 4SA, UK.

Tel.: 01312421383

Fax: 01312421387

E-mail: euan.sandilands@luht.scot.nhs.uk

\section{Keywords}

chronic kidney disease, glomerular

filtration rate, renal dysfunction

\section{Received}

25 January 2013

Accepted

7 June 2013

Accepted Article

Published Online

26 June 2013

Chronic kidney disease affects millions of people worldwide and is associated with an increased morbidity and mortality as a result of kidney failure and cardiovascular disease. Accurate assessment of kidney function is important in the clinical setting as a screening tool and for monitoring disease progression and guiding prognosis. In clinical research, the development of new methods to measure kidney function accurately is important in the search for new therapeutic targets and the discovery of novel biomarkers to aid early identification of kidney injury. This review considers different methods for measuring kidney function and their contribution to the improvement of detection, monitoring and treatment of chronic kidney disease.

\section{Introduction}

Chronic kidney disease (CKD) is common and associated with an increased mortality, frequently as a result of kidney failure and cardiovascular disease [1-3]. Chronic kidney disease has been described as a worldwide public health problem [2], with a prevalence of $\sim 12 \%$ in the USA [4] and Europe [5]. In the USA, there are around 19 million adults with CKD and it is estimated that more than 2 million people will require dialysis or transplantation by the year 2030 [3]. Criteria outlined by the National Kidney Foundation Kidney Disease Outcomes Quality Initiative (KDOQI) [6] define chronic kidney disease as kidney damage present for more than 3 months with or without a decrease in glomerular filtration rate (GFR), or a reduction in GFR for more than 3 months with or without kidney damage. Kidney damage itself is defined as structural or functional abnormalities of the kidney manifest by either pathological abnormalities or markers of kidney damage, e.g. proteinuria. Chronic kidney disease is categorized into five stages based on the estimated GFR (eGFR; Table 1). Proteinuria, included within the classification as a marker of kidney damage, has been identified as an independent risk factor for CKD progression, cardiovascular disease and overall mortality [7-9]. International adoption of this system has facilitated both clinicians and researchers in the identification, diagnosis and management of CKD, and aided large-scale epidemiological studies examining the prevalence of CKD and the implications of severity with respect to clinical outcome $[6,7]$.

Accurate measurement of kidney function is methodologically difficult because the kidney has several different interlinked functions, including regulation of water and electrolytes, excretion of waste products, acid-base homeostasis and hormone secretion. In the clinical setting, surrogate markers and prediction formulae are often used, while in the research arena clinical trials may necessitate a more precise determination of kidney function. This review considers a number of different methods to measure kidney function in both the clinic and the research setting.

\section{Glomerular filtration rate}

Glomerular filtration rate is considered the best overall measurement of kidney function and correlates well with disturbance in renal function [10-12]. A normal GFR is $\sim 130 \mathrm{ml} \mathrm{min}{ }^{-1} 1.73 \mathrm{~m}^{-2}$ in males and 


\section{Table 1}

Stages of chronic kidney disease with clinical management plan from [6]

\begin{tabular}{|c|c|c|c|}
\hline CKD stage & Description & GFR $\left(\mathrm{ml} \mathrm{min}{ }^{-1} 1.73 \mathrm{~m}^{-2}\right)$ & Action \\
\hline 1 & Kidney damage with normal or increased GFR & $>90$ & $\begin{array}{l}\text { Diagnosis and treatment } \\
\text { Treatment of comorbid conditions } \\
\text { Slowing progression } \\
\text { CVD risk reduction }\end{array}$ \\
\hline 2 & Kidney damage with mild reduction of GFR & $60-89$ & Estimating progression \\
\hline 3 & Moderate decrease of GFR & $30-59$ & Evaluating and treating complications \\
\hline 4 & Severe reduction of GFR & $15-29$ & Preparation for kidney replacement therapy \\
\hline 5 & Kidney failure & $<15$ (or dialysis) & Replacement (if uraemia present) \\
\hline
\end{tabular}

Abbreviations are as follows: CKD, chronic kidney disease; CVD, cardiovascular disease; and GFR, glomerular filtration rate. Source of information and where additional information can be found: http://www.kidney.org/professionals/kdoqi/guidelines_ckd/toc.htm

$\sim 120 \mathrm{ml} \mathrm{min}^{-1} 1.73 \mathrm{~m}^{-2}$ in females. Kidney function is proportional to kidney size which, in turn, is proportional to body surface area and so adjustment is necessary when comparing GFR with normal values. Interindividual variation exists, however, depending on body mass, protein intake, exercise and diurnal variation. Glomerular filtration rate cannot be measured directly in humans but instead can be determined by plasma clearance of a filtration marker into the urine. An ideal filtration marker is one that is physiologically inert, with a low molecular weight allowing free filtration at the glomerulus, is not bound to plasma proteins and does not itself alter renal function [10]. Additionally, filtration markers must be able to achieve a stable plasma concentration without being reabsorbed, secreted or metabolized by the kidney. A number of exogenous [inulin, iothalamate, ethylenediaminetetra-acetic acid (EDTA) and iohexol] and endogenous filtration markers (creatinine and cystatin C) have been studied and will be discussed in more detail.

\section{Exogenous filtration markers}

Inulin Urinary clearance of inulin, a 5200 Da inert polymer of fructose derived from plant tubers, is considered the 'gold standard' measurement of GFR [11]. Inulin is freely filtered at the glomerulus and is not reabsorbed, synthesized or metabolized by the tubules. The classic method of urinary clearance involves fasting subjects prior to administration of a priming dose of inulin followed by a continuous intravenous infusion [13]. Once steady state is achieved, repeated timed urine and blood samples are collected, and GFR can be derived from the concentration of inulin in plasma $(P)$, urine $(U)$ and the urine flow rate $(V)$ using the formula: GFR $=U V / P$. Methodological limitations are associated with the use of this method, however, not least due to the strictly timed urine collections, which are not only challenging for both patient and clinician but may even necessitate urinary catheterization.

Earle and Berliner (1946) [14] described an alternative infusion technique avoiding the need for timed urine col- lections. This method was based on the concept that inulin is exclusively eliminated via the renal pathway and therefore, in steady state, the rate of excretion equals the rate of infusion [15]. The GFR (in millilitres per minute) may be calculated by dividing the rate of the infusion (in milligrams per minute) by the plasma concentration (in milligrams per millilitre). While this method gives reproducible results $[16,17]$, it is hard to achieve a constant plasma inulin concentration, and small changes in inulin concentration can significantly affect the calculated GFR [10]. Furthermore, animal and human studies demonstrate that complete equilibration of inulin in body fluids, necessary for accurate GFR calculation, can take several hours to achieve $[17,18]$. As a result, serum inulin concentrations are often lower than expected, which in turn leads to an overestimation of GFR, frequently exceeding urinary inulin clearance by $\sim-10 \mathrm{ml} \mathrm{min}^{-1}[17,19]$.

While inulin continues to be useful particularly for mechanistic studies, especially when coupled with measurement of renal clearance of para-aminohippuric acid (PAH) to assess renal plasma flow $[20,21]$, it is seldom used nowadays, partly due to the complex methodology described above but also as a result of limitations in the supply of this agent. Nevertheless, the classic urinary inulin clearance method remains the benchmark by which newer, and often simpler, methods of GFR assessment are compared.

Radioisotope filtration markers Radioisotopically labelled agents were introduced in the 1960s as an alternative method of GFR measurement. Compounds such as ${ }^{125} \mathrm{I}-$ iothalamate, ${ }^{51} \mathrm{Cr}$-ethylenediaminetetra-acetic acid $\left({ }^{51} \mathrm{Cr}\right.$ EDTA) and ${ }^{99 m}$ Tc-diethylenethiaminetetra-acetic acid ( ${ }^{99 m}$ Tc-DTPA) possess a low molecular weight, show minimal plasma protein binding, and clearance can be calculated from plasma concentration-time curves following single-dose administration, avoiding the practical difficulties associated with continuous infusions and repeated urine sampling $[10,22]$. These agents, however, are 
expensive, unsuitable for use in women of childbearing age, and require strict precautions during their handling and disposal [23]. Furthermore, important differences in their clearance have been highlighted, suggesting that their use as accurate filtration markers may be limited. Clearance of ${ }^{125}$-iothalamate exceeds that of both inulin and ${ }^{51} \mathrm{Cr}$-EDTA, leading to an overestimation of GFR $[22,24$, 25]. This difference can be reduced by pretreatment with probenicid, suggesting that ${ }^{125}$-iothalamate undergoes tubular secretion. Although no difference has been demonstrated between clearance of ${ }^{51} \mathrm{Cr}$-EDTA and ${ }^{99 \mathrm{~m} T \mathrm{~T}-\mathrm{DTPA}}$ [26], plasma clearance of both markers exceeds urinary clearance, suggesting that these agents undergo a degree of extrarenal elimination, thereby limiting their use for accurate measurements of GFR [26]. While these differences may preclude their use to provide an accurate measure of GFR, particularly in the context of clinical trials, they may have some role as a guide of GFR over time in the clinical setting.

Radiographic contrast agents Radiographic contrast agents have been used as markers of GFR because their use avoids the methodological difficulties associated with inulin clearance techniques and the practical restrictions associated with radioactive material. Nonradioactive iothalamate and iohexol have both been used, with the latter being more attractive due to its lower allergenic potential [27]. lohexol is not secreted, metabolized or reabsorbed by the kidneys, is less than $2 \%$ protein bound and undergoes exclusive renal elimination, with the total amount injected being recovered from the urine within $12 \mathrm{~h}[28,29]$. It can be measured in the serum following a single bolus injection by high-perfomance liquid chromatography, and a good correlation has been demonstrated using a one- or two-compartment model between total body clearance and urinary clearance of inulin across a wide range of GFRs $[27,29]$.

\section{Endogenous filtration markers}

Creatinine Serum creatinine is the most commonly used endogenous glomerular filtration marker in clinical practice $[23,30]$. Creatinine is predominantly formed from creatine and phosphocreatine in skeletal muscle [10], with a small contribution from ingestion of meat [31]. It is freely filtered by the glomerulus without being reabsorbed or metabolized, and its use avoids the need for administration of expensive exogenous agents. The use of serum creatinine as a surrogate for GFR, however, is limited by a number of patient-dependent and -independent factors.

Creatinine production not only differs between individuals and over time in association with changes in muscle mass and diet, but it has also been shown to undergo tubular secretion in addition to glomerular filtration [11, 23], potentially leading to an overestimation of GFR. The degree of tubular secretion varies between, and even within, individuals [32], and may also be affected by medication, such as cimetidine and trimethoprim $[33,34]$. Extrarenal elimination of creatinine via the gastrointestinal tract, particularly in advanced renal failure, further contributes to an overestimation of the GFR [11, 23, 35]. While accuracy may be improved through measurement of creatinine clearance by means of a timed urine collection together with measurement of serum creatinine concentration [creatinine clearance $(\mathrm{CrCl})=$ (urine creatinine concentration $\times$ urine volume)/serum creatinine concentration], urine collections are cumbersome to perform, costly and subject to error. It was recognized in the 1980s that creatinine concentration may remain within the standard reference range in a substantial proportion of patients with significantly reduced GFRs [36]; thus, the use of creatinine as a marker of GFR is questionable. More recently, however, Spanaus et al. [37] demonstrated good diagnostic perfomance of serum creatinine in detecting even minor deterioration in renal function. Prediction of progression was also similar between creatinine and other biomarkers, such as cystatin C. Our negative perception of creatinine as a marker of GFR may partly be due to inappropriate reliance on reference ranges and, through longitudinal monitoring, identification of small, but clinically important, changes in creatinine concentration will ensure detection of deterioration in renal function [38]. Nevertheless, the variability surrounding creatinine production and tubular secretion preclude it from being used as an accurate measure in clinical trials, although it does remain a worthy clinical tool for estimation of GFR.

Cystatin C Cystatin C has been proposed as an alternative endogenous glomerular filtration marker. This cationic nonglycosylated cysteine proteinase is produced at a constant rate by all nucleated cells [39] and, owing to its low molecular weight, is freely filtered by the glomerulus and almost completely reabsorbed and degraded by proximal tubular cells [40]. As it is completely cleared from the circulation, it supports the hypothesis that the serum concentration will reflect the GFR assuming the production rate remains constant [39]. Unlike creatinine, production of cystatin $C$ is unaffected by muscle mass or diet, and remains constant even in the presence of intercurrent infection or malignancy [39]. Most [39, 41-45], although not all studies [37, 46, 47], including a meta-analysis [30], have demonstrated superiority of cystatin $C$ as a measure of GFR in comparison to serum creatinine. However, cystatin $C$ is ubiquitous, and many other factors, including age, male gender, weight, height, smoking and steroid therapy, have been shown to be associated independently with higher serum cystatin C levels after adjustment for renal function, suggesting that it may lack specificity for renal impairment $[48,49]$. Additionally, thyroid disease has been shown to have a major influence on cystatin $C$ concentration and so measurement of this marker should be avoided in those with abnormal thyroid function [50].Traditional clearance techniques are more labour and time 
intensive and are associated with greater patient inconvenience than measurement of cystatin $C$. However, the cost-effectiveness of measurement of cystatin $C$ against the more traditional and cheaper method of serum creatinine will play an important role in determining uptake of this method [30].

\section{Estimated GFR}

Prediction equations based on the serum creatinine have been developed as a simple, rapid means of estimating GFR to monitor disease progression and aid treatment decisions. This is particularly valuable in the clinical setting, where it avoids the need for potentially invasive, timeconsuming and complex methods of GFR assessment. The Cockcroft and Gault equation was one of the first such formulae to be developed, estimating creatinine clearance based on serum creatinine concentration, age, sex and weight [51]. Although use of this equation quickly became widespread, it systematically overestimates GFR as a result of tubular secretion of creatinine. The GFR is further overestimated in the presence of obesity or fluid overload, where an increase in weight may not necessarily reflect an increase in muscle mass [11, 23]. In 1999, Levey et al. [52] developed an equation based on the Modification of Diet in Renal Disease (MDRD) Study, a multicentre study evaluating the effect of dietary protein restriction and strict blood pressure control on the progression of renal disease in patients with CKD. This equation was based on serum creatinine concentration, demographic characteristics (age, sex and ethnicity) and serum urea and albumin levels. Subsequently, a four-variable MDRD equation was developed based on age, sex, ethnicity and serum creatinine levels to simplify clinical use $[6,53]$. While the exclusion of weight reduces error associated with obesity and fluid retention, inclusion of ethnicity accounts for the higher than average serum creatinine values present in the black population [52]. The MDRD formula has been validated in different patient groups [54,55], and the four-variable equation has now become the most widely used equation in clinical practice [56]. It is less accurate, however, in patients with GFR values near or above $60 \mathrm{ml} \mathrm{min}^{-1} 1.73 \mathrm{~m}^{-2}$ [56]. Variability in the calibration of serum creatinine assays may introduce error, particularly at high levels of GFR $[57,58]$. The four-variable MDRD equation has now been re-expressed with a standardized serum creatinine assay demonstrating more accurate GFR estimates [53]. Important differences in the performance of the MDRD equation depending on ethnicity have also been demonstrated in the Chinese, Japanese and Indian populations [59-62]. More recently, a formula based upon serum cystatin C concentration has been developed [6366]. While this has been shown to demonstrate greater accuracy in detection of GFR values either below or above $60 \mathrm{ml} \mathrm{min}-1.73 \mathrm{~m}^{-2}$ in patients with CKD, as with the creatinine-based formula, the equation lacked precision and underestimated the actual measured GFR [65]. The
Chronic Kidney Disease Epidemiology Collaboration (CKDEPI) [4] have developed an equation based on data pooled from 10 studies, with an additional 16 studies used as validation. This equation gives improved accuracy, particularly at higher GFR values. However, it performs less well at lower GFR values, demonstrating that neither equation is optimal across all populations, and the use of a single equation requires an understanding of reduced accuracy at either higher or lower GFR values [67]. It remains unclear whether the accuracy of creatinine-based equations to estimate GFR could be usefully improved by adding further variables.

Although widespread in the clinical setting, prediction formulae lack accuracy particularly in patients with an unusual body habitus or diet, in the presence of rapidly changing renal function, or where GFR values are $>60 \mathrm{ml} \mathrm{min}^{-1} 1.73 \mathrm{~m}^{-2}$ [11]. While the implications of these imprecisions may have less importance in the clinical setting, where trends in kidney function are monitored, estimates of GFR using prediction formulae lack the accuracy required in clinical trials.

\section{Assessment of proteinuria}

Proteinuria is an important independent marker in the evaluation and management of CKD. It is associated with an increased risk of CKD progression, cardiovascular disease and all-cause mortality $[7,68-70]$. A reduction in proteinuria with drugs that block the renin-angiotensin system can lead to a slowing, or even reversal, of CKD progression [71] and a reduction in cardiovascular risk [72], highlighting this as an important therapeutic target.

Urinary protein originates primarily from glomerular filtration of plasma proteins, such as albumin [69]. Nonplasma proteins, such as uromodulin, produced by the tubular epithelium or lower urinary tract, are also present, along with a variable proportion of immunoglobulins and low-molecular-weight proteins. Normally, only a small amount of protein is excreted in the urine. Proteinuria $\left(>300 \mathrm{mg} \mathrm{day}^{-1}\right)$ refers to increased urinary excretion of total protein (albumin plus other specific protein), while albuminuria specifically describes increased urinary excretion of albumin [6]. Microalbuminuria ( $>30 \mathrm{mg}$ urinary albumin day $^{-1}$ ) describes albumin excretion above the normal range but below the level of detection by tests for total protein [6]. A $24 \mathrm{~h}$ collection is the gold-standard method of urinary protein quantification. While this may still be useful in some patients (e.g. in the presence of severe proteinuria, in the extremes of age and weight, or where creatinine excretion is not constant), it is a costly approach, and patient inconvenience can often lead to incomplete collections and inaccurate assessment of proteinuria $[6,73]$. As the excretion of creatinine and protein, in the presence of a stable GFR, is constant throughout the day, use of a ratio measurement of protein to creatinine 
[protein-creatinine ratio $(P C R)$ ] or albumin to creatinine [albumin-creatinine ratio (ACR)] on a single 'spot' urine sample has now become a widespread clinical screening tool [73]. The test is quick, cheap, more convenient and, in the presence of stable renal function, correlates well with $24 \mathrm{~h}$ urine protein and albumin values $[74,75]$ across a variety of patient populations $[69,74,76-78]$ and has been shown to predict renal outcome and death $[79,80]$. There is no consensus on whether proteinuria or albuminuria should be measured in the assessment of patients with CKD. Although more expensive, urinary ACR is the most appropriate first-line test for the detection of proteinuria in diabetic nephropathy, because it has been demonstrated to provide a more sensitive, quantitative and standardized measurement of loss of protein, particularly at low levels, in most nephropathies [81]. The KDOQI advises that for screening adults at risk of CKD and for monitoring progression of CKD, urinary ACR is preferred, but urinary PCR is acceptable if the ACR is more than $500-1000 \mathrm{mg} \mathrm{g}^{-1}$ [6]. The National Institute for Health and Clinical Excellence (NICE) [82] advises the use of urinary ACR for the detection and identification of proteinuria in the diagnosis of CKD because it has greater sensitivity for low levels of proteinuria. The Scottish Intercollegiate Guidelines Network (SIGN) [83], while recommending the use of urinary ACR for the detection and monitoring of diabetic nephropathy, recognizes that its use in patients with CKD without diabetes must be weighed against its greater cost, meaning that urinary PCR is often favoured. While use of proteinuria has been supported as a surrogate outcome to facilitate clinical trials [84], the role of PCR and ACR, where absolute levels of proteinuria are essential to monitor response to drug therapy, is less clear. Both PCR and ACR show similar accuracy and repeatability to $24 \mathrm{~h}$ urine protein [85]. Indeed, some drug trials have already used PCR as a surrogate for $24 \mathrm{~h}$ urine protein [86]. However, there is a need for a randomized controlled trial comparing all three methods in the quantification of proteinuria with respect to stage and progression of CKD in a variety of patient populations before the $24 \mathrm{~h}$ urinary collection is completely superseded by spot urine sampling [85].

\section{Renal plasma flow}

Assessment of renal clearance of PAH is the gold-standard measurement of renal plasma flow (RPF) $[16,87]$ and, typically, clearance of PAH and inulin are measured simultaneously to assess RPF and GFR, respectively. Paraaminohippuric acid is both freely filtered by the glomerulus and secreted by the proximal tubule [87, 88], and measurement of PAH clearance is based on the principle that renal clearance can be used to determine RPF if a substance is completely extracted in a single transit through the kidneys. At low concentrations, renal clearance of PAH approximates RPF. As the concentration of PAH rises, and the tubular transport mechanism becomes saturated, however, extraction of PAH reduces, leading to an underestimation of RPF [87]. Interindividual variation also exists in the extraction ratio of $\mathrm{PAH}$, particularly in the presence of renal failure, such that it is difficult to assess RPF accurately without determination of renal venous plasma concentration, which is impractical in clinical practice [87].

As with traditional inulin clearance studies, there are methodological limitations to this technique. Additionally, some medications (such as trimethoprim and sotalol) containing a para-aminobenzoic ring may reduce the reliability of PAH clearance through interference with the assay in the laboratory [88]. As with inulin, an alternative infusion technique allowing clearance to be measured without urine sampling has been described [14]. This technique is more straightforward and avoids the need for exact timing of serum and urine samples and any potential requirement for urinary catheterization. However, while some have demonstrated a good correlation with the classic renal clearance method [16], others suggest that this method lacks the accuracy and precision of the urinary clearance method [87].

\section{Novel biomarkers for CKD}

Chronic kidney disease is rising in prevalence [89]. Disease progression can be slowed and prognosis improved if appropriate treatment is instituted at an early stage. Traditional biomarkers commonly used to identify and monitor kidney function and progression of CKD include serum creatinine, as a surrogate for GFR, and the presence of proteinuria. These biomarkers, however, have limitations. Glomerular filtration rate reflects late changes in kidney function [90] because hyperfiltration and compensatory hypertrophy of remaining healthy nephrons can maintain GFR in the face of significant functional loss [91]. Proteinuria may also identify a disease process that is already well established [92], and may not be present in some types of renal injury [93]. As an association between acute kidney injury (AKI) and the incidence and progression of CKD has become appreciated [94,95], identification of sensitive and specific novel biomarkers of cell injury which may predict disease progression before abnormalities in traditional parameters of renal function are evident has become an area of intense research.

Neutrophil gelatinase-associated lipocalin (NGAL) is a protein expressed in renal tubular cells, which has been shown in animal and human studies to be released in response to harmful stimuli, such as ischaemia or infection [96-98]. Release of NGAL is rapid, occurring within a few hours of kidney injury, before any change in creatinine or GFR, demonstrating its potential use as a real-time indicator of active kidney injury [98]. While the role of NGAL as a marker of AKI has been extensively investigated [98], increased concentrations of NGAL in the urine and plasma 
have also been shown in patients with CKD [99]. Bolignano et al. [100] demonstrated a direct correlation between urinary NGAL concentration and proteinuria, and an inverse relationship with residual renal function in patients with membranous glomerulonephritis, such that patients with higher urinary NGAL levels experienced greater reductions in kidney function. Another study of 96 patients with various aetiologies of CKD stages 2-4 showed that urinary and serum NGAL at baseline were directly associated with the progression of CKD over 18 months, independent of other confounders, such as age and eGFR [101]. Plasma NGAL levels were also shown to be inversely proportional to GFR in a study of 45 children with CKD stages 2-4 [102]. More recent studies suggest that NGAL may be useful not only in the prediction of CKD progression but also in the monitoring of response to treatment $[103,104]$. Changes in urinary NGAL, however, are not specific to renal disease, and other conditions have been shown to have an influence, such as infection, inflammation, malignancy and hypertension [105, 106]. Further large-scale studies are required to explore the pathophysiological role of NGAL and its potential use in the detection, staging and prediction of progression of CKD.

Kidney injury molecule-1 (KIM-1) is a type I cellmembrane glycoprotein containing a unique six-cysteine immunoglobulin-like domain and mucin domain in its extracelluclar region [107]. Kidney injury molecule- 1 is undetectable in healthy kidneys, but this phagocytosis receptor is upregulated in the proximal tubule of the injured kidney and is detectable in the urine of animals and humans following ischaemic kidney injury $[107,108]$. As a result, KIM-1 may be a useful biomarker for the early identification of AKI $[109,110]$ and its clinical outcomes [111]. The recent development of a rapid urine dipstick test for KIM-1 [112] will serve to facilitate further evaluation of this marker as a rapid, bedside clinical test. The potential role of KIM-1 in CKD is less clear. In a study of patients with CKD from various aetiologies, KIM-1 was expressed at the luminal side of dedifferentiated proximal tubules in areas of fibrosis and inflammation and correlated positively with kidney damage and negatively with renal function [113]. The same research group also showed KIM-1 to be an independent predictor of long-term graft loss in renal transplant recipients, apparently independent of creatinine clearance, proteinuria and donor age [114]. Others have shown that KIM-1 may have a role not only in the identification and prediction of progression of CKD but also in the response to treatment. A retrospective study of 34 nondiabetic patients with CKD and proteinuria showed a parallel reduction in proteinuria and KIM-1 following treatment with a low-salt diet, angiotensin II antagonist and diuretic [115]. More recently, however, it has been shown in diabetic patients with CKD that, despite an association between KIM-1 and increased mortality, measurement of urinary KIM-1 offered no additional prognostic information beyond that already available through established risk factors [116].

Other biomarkers have been identified, including livertype fatty acid binding protein (L-FABP) and asymmetric dimethylarginine (ADMA). Liver-type fatty acid binding protein is expressed in the proximal tubule, and expression has been shown to be upregulated in AKI [117] and CKD [118]. In this latter study of patients with nondiabetic CKD, urine L-FABP levels correlated with urine protein and were significantly higher in patients who progressed to more severe disease. Asymmetric dimethylarginine is an endogenous nitric oxide synthase inhibitor that is metabolized in glomerular endothelial and tubular epithelial cells [90, 119]. Kidney dysfunction interferes with this metabolism, leading to increased levels of ADMA. Animal studies have shown that increased ADMA levels result in reduced nitric oxide production, which contributes to progressive kidney damage [120]. Asymmetric dimethylarginine has, therefore, been proposed as both a biomarker and a potential target for therapy for CKD [119].

Advances in basic science have helped to develop our understanding of the pathophysiological processes of renal disease and identified promising biomarkers that reflect severity and disease progression. It remains a challenge to translate these findings into therapeutic approaches to identify those at risk of CKD and halt its progression [121]. The European Medicines Agency and the US Food and Drug Administration have approved the use of some urinary biomarkers for the detection of acute drug-induced nephrotoxicity in the context of preclinical drug development [122]. It is recognized that further exploration of the use of biomarkers, such as KIM-1, for the detection of AKI is worthwhile because they provide additional information. The role of these biomarkers in CKD, however, is less clear. Much of the work to date involves small, single-centre studies describing statistically signficant results but lacking information on sensitivity and specificity necessary to determine the usefulness of the biomarker [90]. Further larger scale multicentre randomized controlled trials are required to assess the role of these markers in CKD before they can be incorporated as end-points in research studies or used to inform and guide clinical practice.

\section{Magnetic resonance imaging}

Progression of CKD is characterized by ongoing tubulointerstitial injury causing tubular atrophy and interstitial fibrosis. Renal tissue hypoxia is hypothesized to be central to the pathogenesis of renal injury and, on reaching a certain threshold, a common, irreversible pathway of progressive renal decline occurs, independent of the initial insult [123-125]. Chronic hypoxia is likely to be multifactorial, secondary to tubulo-interstitial ischaemia, as a result of renal arteriolar and arterial damage, peritubular capillary 
loss due to fibrosis, glomerular damage causing a reduction in peritubular perfusion, an imbalance in vasoactive substances causing intrarenal vasoconstriction, and the development of anaemia contributing to reduced oxygen delivery [123]. Recent studies have investigated the use of functional magnetic resonance imaging (MRI) to evaluate renal parenchymal fibrosis and hypoxia [124]. Diffusionweighted (DW)-MRI and blood oxygen level-dependent (BOLD)-MRI are two non-invasive techniques that may provide valuable information in predicting disease progression and developing new treatment targets in CKD. These techniques avoid not only the need for potentially harmful exogenous iodinated radiographic contrast agents but also gadolinium-based contrast agents, which have been associated with nephrogenic systemic fibrosis [126]. Diffusion-weighted MRI is a technique used to measure molecular movement within tissues. The apparent diffusion coefficient is calculated from the DW-MRI images and combines the effects of capillary perfusion and water diffusion in the extracellular extravascular space [127]. Diffusion-weighted MRI provides information on perfusion and diffusion simultaneously and may be used to differentiate between normal and abnormal tissues. Studies in animals [128] and humans [129] demonstrate that use of this technique may be feasible in the assessment and detection of the early stages of CKD.

Blood oxygen level-dependent MRI is a non-invasive technique for assessing renal oxygenation using deoxyhaemoglobin as an endogenous marker. It has been used to demonstrate not only enhanced concentration of deoxygenated haemoglobin within the renal medulla in humans with CKD when compared with those having healthy kidneys [125], but also a reduced oxygenation level-dependent signal following angiotensin II antagonism, suggesting that angiotensin II may have an important role in the generation of renal hypoxia in CKD [130]. Despite these positive findings, Michaely et al. [131] demonstrated no signficant differences in signal of the cortex and medulla between patient age, sex, eGFR and stage of CKD, suggesting that BOLD-MRI cannot discriminate between patients with various stages of CKD. While DW-MRI and BOLD-MRI may have a role in the detection of parenchymal hypoxia in CKD, further studies are needed to investigate whether these techniques may be used in the clinical setting to identify and stage disease and to provide prognostic information and, in the research arena, to develop new treatment targets for CKD.

\section{Conclusion}

Measurement of renal function is complex. The kidneys serve a variety of roles within the body, and no individual method of measurement provides an accurate overall assessment of renal function. In the clinical setting, the monitoring of trends, particularly of GFR, is often all that is necessary to guide treatment decisions and predict prognosis. In clinical trials aimed at developing and assessing the effect of new drugs, however, a more precise measurement is required. Significant developments have been made in the field of novel biomarkers and radiological imaging, but whether these modalities will ultimately supersede the more traditional methods remains to be determined. Until then, a combination of assessment modalities may provide the best overall measure of kidney function and enable early prediction of CKD, as well as the development of new treatments aimed at slowing progression of renal dysfunction.

\section{Competing Interests}

All authors have completed the Unified Competing Interest form at http://www.icmje.org/coi_disclosure.pdf (available on request from the corresponding author) and declare: no support from any organization for the submitted work; no financial relationships with any organizations that might have an interest in the submitted work in the previous 3 years; no other relationships or activities that could appear to have influenced the submitted work.

\section{REFERENCES}

1 Levey AS, Tangri N, Stevens LA. Classification of chronic kidney disease: a step forward. Ann Intern Med 2011; 154 : 65-7.

2 Levey AS, Andreoli SP, DuBose T, Provenzano R, Collins AJ. CKD: common, harmful, and treatable - World Kidney Day 2007. Am J Kidney Dis 2007; 49: 175-9.

3 Coresh J, Byrd-Holt D, Astor BC, Briggs JP, Eggers PW, Lacher DA, Hostetter TH. Chronic kidney disease awareness, prevalence, and trends among U.S. adults, 1999 to 2000. JASN 2005; 16: 180-8.

4 Levey AS, Stevens LA, Schmid CH, Zhang YL, Castro AF, 3rd, Feldman HI, Kusek JW, Eggers P, Van Lente F, Greene T, Coresh J. A new equation to estimate glomerular filtration rate. Ann Intern Med 2009; 150: 604-12.

5 de Zeeuw D, Hillege HL, de Jong PE. The kidney, a cardiovascular risk marker, and a new target for therapy. Kidney Int Suppl 2005; 98: S25-9.

$6 \mathrm{~K} / \mathrm{DOQ}$ clinical practice guidelines for chronic kidney disease: evaluation, classification, and stratification. Am J Kidney Dis 2002; 39: S1-266.

7 Hemmelgarn BR, Manns BJ, Lloyd A, James MT, Klarenbach S, Quinn RR, Wiebe N, Tonelli M. Relation between kidney function, proteinuria, and adverse outcomes. JAMA 2010; 303: 423-9.

8 Hemmelgarn BR, Manns BJ, Straus S, Naugler C, Holroyd-Leduc J, Braun TC, Levin A, Klarenbach S, Lee PF, 
Hafez K, Schwartz D, Jindal K, Ervin K, Bello A, Turin TC, McBrien K, Elliott M, Tonelli M. Knowledge translation for nephrologists: strategies for improving the identification of patients with proteinuria. J Nephrol 2012; 25: 933-43.

9 Matsushita K, Ballew SH, Astor BC, Jong PE, Gansevoort RT, Hemmelgarn BR, Levey AS, Levin A, Wen CP, Woodward M, Coresh J. Cohort profile: the chronic kidney disease prognosis consortium. Int J Epidemiol 2012. [epub ahead of print].

10 Rahn KH, Heidenreich S, Bruckner D. How to assess glomerular function and damage in humans. J Hypertens 1999; 17: 309-17.

11 Stevens LA, Coresh J, Greene T, Levey AS. Assessing kidney function-measured and estimated glomerular filtration rate. N Engl J Med 2006; 354: 2473-83.

12 Stevens LA, Levey AS. Measured GFR as a confirmatory test for estimated GFR. JASN 2009; 20: 2305-13.

13 Smith HW, Goldring W, Chasis H. The measurement of the tubular excretory mass, effective blood flow and filtration rate in the normal human kidney. J Clin Invest 1938; 17: 263-78.

14 Earle DP, Jr, Berliner RW. A simplified clinical procedure for measurement of glomerular filtration rate and renal plasma flow. Proc Soc Exp Biol Med 1946; 62: 262-4.

15 Berger EY, Farber SJ, Earle DP, Jr. Comparison of the constant infusion and urine collection techniques for the measurement of renal function. J Clin Invest 1948; 27 : 710-6.

16 Schnurr E, Lahme W, Kuppers H. Measurement of renal clearance of inulin and PAH in the steady state without urine collection. Clin Nephrol 1980; 13: 26-9.

17 Hellerstein S, Berenbom M, Alon U, Warady BA. The renal clearance and infusion clearance of inulin are similar, but not identical. Kidney Int 1993; 44: 1058-61.

18 Cotlove E. Mechanism and extent of distribution of inulin and sucrose in chloride space of tissues. Am J Physiol 1954; 176: 396-410.

19 Florijn KW, Barendregt JN, Lentjes EG, van Dam W, Prodjosudjadi W, van Saase JL, van Es LA, Chang PC. Glomerular filtration rate measurement by 'single-shot' injection of inulin. Kidney Int 1994; 46: 252-9.

20 Dhaun N, Maclntyre IM, Kerr D, Melville V, Johnston NR, Haughie S, Goddard J, Webb DJ. Selective endothelin-A receptor antagonism reduces proteinuria, blood pressure, and arterial stiffness in chronic proteinuric kidney disease. Hypertension 2011; 57: 772-9.

21 Sandilands EA, Cameron S, Paterson F, Donaldson S, Briody L, Crowe J, Donnelly J, Thompson A, Johnston NR, Mackenzie I, Uren N, Goddard J, Webb DJ, Megson IL, Bateman N, Eddleston M. Mechanisms for an effect of acetylcysteine on renal function after exposure to radio-graphic contrast material: study protocol. BMC Clin Pharmacol 2012; 12: 3.

22 Odlind B, Hallgren R, Sohtell M, Lindstrom B. Is 125I iothalamate an ideal marker for glomerular filtration? Kidney Int 1985; 27: 9-16.
23 Traynor J, Mactier R, Geddes CC, Fox JG. How to measure renal function in clinical practice. BMJ 2006; 333: 733-7.

24 Perrone RD, Steinman TI, Beck GJ, Skibinski Cl, Royal HD, Lawlor M, Hunsicker LG. Utility of radioisotopic filtration markers in chronic renal insufficiency: simultaneous comparison of 125I-iothalamate, 169Yb-DTPA, 99mTc-DTPA and inulin. The Modification of Diet in Renal Disease Study. Am J Kidney Dis 1990; 16: 224-35.

25 Israelit AH, Long DL, White MG, Hull AR. Measurement of glomerular filtration rate utilizing a single subcutaneous injection of 125I-iothalamate. Kidney Int 1973; 4: 346-9.

26 Rehling M, Moller ML, Thamdrup B, Lund JO, Trap-Jensen J. Simultaneous measurement of renal clearance and plasma clearance of $99 \mathrm{mTc}$-labelled diethylenetriaminepenta-acetate, $51 \mathrm{Cr}$-labelled ethylenediaminetetra-acetate and inulin in man. Clin Sci (Lond) 1984; 66: 613-9.

27 Gaspari F, Perico N, Ruggenenti P, Mosconi L, Amuchastegui CS, Guerini E, Daina E, Remuzzi G. Plasma clearance of nonradioactive iohexol as a measure of glomerular filtration rate. JASN 1995; 6: 257-63.

28 Krutzen E, Back SE, Nilsson-Ehle I, Nilsson-Ehle P. Plasma clearance of a new contrast agent, iohexol: a method for the assessment of glomerular filtration rate. J Lab Clin Med 1984; 104: 955-61.

29 Schwartz GJ, Furth S, Cole SR, Warady B, Munoz A. Glomerular filtration rate via plasma iohexol disappearance: pilot study for chronic kidney disease in children. Kidney Int 2006; 69: 2070-7.

30 Dharnidharka VR, Kwon C, Stevens G. Serum cystatin C is superior to serum creatinine as a marker of kidney function: a meta-analysis. Am J Kidney Dis 2002; 40: 221-6.

31 Mayersohn M, Conrad KA, Achari R. The influence of a cooked meat meal on creatinine plasma concentration and creatinine clearance. Br J Clin Pharmacol 1983; 15: 227-30.

32 Berlyne GM, Varley H, Nilwarangkur S, Hoerni M. Endogenous-creatinine clearance and glomerular-filtration rate. Lancet $1964 ; 2: 874-6$.

33 Dubb JW, Stote RM, Familiar RG, Lee K, Alexander F. Effect of cimetidine on renal function in normal man. Clin Pharmacol Ther 1978; 24: 76-83.

34 Berglund F, Killander J, Pompeius R. Effect of trimethoprim-sulfamethoxazole on the renal excretion of creatinine in man. J Urol 1975; 114: 802-8.

35 Stevens LA, Levey AS. Measurement of kidney function. Med Clin North Am 2005; 89: 457-73.

36 Shemesh O, Golbetz H, Kriss JP, Myers BD. Limitations of creatinine as a filtration marker in glomerulopathic patients. Kidney Int 1985; 28: 830-8.

37 Spanaus KS, Kollerits B, Ritz E, Hersberger M, Kronenberg F, von Eckardstein A. Serum creatinine, cystatin C, and beta-trace protein in diagnostic staging and predicting progression of primary nondiabetic chronic kidney disease. Clin Chem 2010; 56: 740-9. 
38 Dalton RN. Serum creatinine and glomerular filtration rate: perception and reality. Clin Chem 2010; 56:687-9.

39 Newman DJ, Thakkar H, Edwards RG, Wilkie M, White T, Grubb AO, Price CP. Serum cystatin $C$ measured by automated immunoassay: a more sensitive marker of changes in GFR than serum creatinine. Kidney Int 1995; 47: 312-8.

40 Filler G, Bokenkamp A, Hofmann W, Le Bricon T, Martinez-Bru C, Grubb A. Cystatin C as a marker of GFR-history, indications, and future research. Clin Biochem 2005; 38: 1-8.

41 Grubb A, Simonsen O, Sturfelt G, Truedsson L, Thysell H. Serum concentration of cystatin C, factor D and beta 2-microglobulin as a measure of glomerular filtration rate. Acta Med Scand 1985; 218: 499-503.

42 Simonsen O, Grubb A, Thysell H. The blood serum concentration of cystatin $C$ (gamma-trace) as a measure of the glomerular filtration rate. Scand J Clin Lab Invest 1985; 45: 97-101.

43 Harmoinen AP, Kouri TT, Wirta OR, Lehtimaki TJ, Rantalaiho V, Turjanmaa VM, Pasternack AI. Evaluation of plasma cystatin $C$ as a marker for glomerular filtration rate in patients with type 2 diabetes. Clin Nephrol 1999; 52: 363-70.

44 Kyhse-Andersen J, Schmidt C, Nordin G, Andersson B, Nilsson-Ehle P, Lindstrom V, Grubb A. Serum cystatin C, determined by a rapid, automated particle-enhanced turbidimetric method, is a better marker than serum creatinine for glomerular filtration rate. Clin Chem 1994; 40: 1921-6.

45 Coll E, Botey A, Alvarez L, Poch E, Quinto L, Saurina A, Vera M, Piera C, Darnell A. Serum cystatin C as a new marker for noninvasive estimation of glomerular filtration rate and as a marker for early renal impairment. Am J Kidney Dis 2000; 36: 29-34.

46 Stickle D, Cole B, Hock K, Hruska KA, Scott MG. Correlation of plasma concentrations of cystatin $C$ and creatinine to inulin clearance in a pediatric population. Clin Chem 1998; 44: 1334-8.

47 Ribichini F, Gambaro G, Graziani MS, Pighi M, Pesarini G, Pasoli P, Anselmi M, Ferrero V, Yabarek T, Sorio A, Rizzotti P, Lupo A, Vassanelli C. Comparison of serum creatinine and cystatin C for early diagnosis of contrast-induced nephropathy after coronary angiography and interventions. Clin Chem 2012; 58: 458-64.

48 Wasen E, Isoaho R, Mattila K, Vahlberg T, Kivela SL, Irjala K. Serum cystatin $C$ in the aged: relationships with health status. Am J Kidney Dis 2003; 42: 36-43.

49 Knight EL, Verhave JC, Spiegelman D, Hillege HL, de Zeeuw D, Curhan GC, de Jong PE. Factors influencing serum cystatin $\mathrm{C}$ levels other than renal function and the impact on renal function measurement. Kidney Int 2004; 65: 1416-21.

50 Kimmel M, Braun N, Alscher MD. Influence of thyroid function on different kidney function tests. Kidney Blood Press Res 2012; 35: 9-17.
51 Cockcroft DW, Gault MH. Prediction of creatinine clearance from serum creatinine. Nephron 1976; 16: 31-41.

52 Levey AS, Bosch JP, Lewis JB, Greene T, Rogers N, Roth D. A more accurate method to estimate glomerular filtration rate from serum creatinine: a new prediction equation. Modification of Diet in Renal Disease Study Group. Ann Intern Med 1999; 130: 461-70.

53 Levey AS, Coresh J, Greene T, Stevens LA, Zhang YL, Hendriksen S, Kusek JW, Van Lente F. Using standardized serum creatinine values in the modification of diet in renal disease study equation for estimating glomerular filtration rate. Ann Intern Med 2006; 145: 247-54.

54 Poge U, Gerhardt T, Palmedo H, Klehr HU, Sauerbruch T, Woitas RP. MDRD equations for estimation of GFR in renal transplant recipients. Am J Transplant 2005; 5: 1306-11.

55 Verhave JC, Fesler P, Ribstein J, du Cailar G, Mimran A. Estimation of renal function in subjects with normal serum creatinine levels: influence of age and body mass index. Am J Kidney Dis 2005; 46: 233-41.

56 Stevens LA, Coresh J, Feldman HI, Greene T, Lash JP, Nelson RG, Rahman M, Deysher AE, Zhang YL, Schmid CH, Levey AS. Evaluation of the modification of diet in renal disease study equation in a large diverse population. JASN 2007; 18: $2749-57$.

57 Coresh J, Astor BC, McQuillan G, Kusek J, Greene T, Van Lente F, Levey AS. Calibration and random variation of the serum creatinine assay as critical elements of using equations to estimate glomerular filtration rate. Am J Kidney Dis 2002; 39: 920-9.

58 Murthy K, Stevens LA, Stark PC, Levey AS. Variation in the serum creatinine assay calibration: a practical application to glomerular filtration rate estimation. Kidney Int 2005; 68 : 1884-7.

59 Ma YC, Zuo L, Chen JH, Luo Q, Yu XQ, Li Y, Xu JS, Huang SM, Wang LN, Huang W, Wang M, Xu GB, Wang HY. Modified glomerular filtration rate estimating equation for Chinese patients with chronic kidney disease. JASN 2006; 17 : 2937-44.

60 Imai E, Horio M, Nitta K, Yamagata K, Iseki K, Hara S, Ura N, Kiyohara $\mathrm{Y}$, Hirakata H, Watanabe T, Moriyama T, Ando $\mathrm{Y}$, Inaguma D, Narita I, Iso H, Wakai K, Yasuda Y, Tsukamoto Y, Ito S, Makino H, Hishida A, Matsuo S. Estimation of glomerular filtration rate by the MDRD study equation modified for Japanese patients with chronic kidney disease. Clin Exp Nephrol 2007; 11:41-50.

61 Mahajan S, Mukhiya GK, Singh R, Tiwari SC, Kalra V, Bhowmik DM, Gupta S, Agarwal SK, Dash SC. Assessing glomerular filtration rate in healthy Indian adults: a comparison of various prediction equations. J Nephrol 2005; 18: 257-61.

62 Praditpornsilpa K, Townamchai N, Chaiwatanarat T, Tiranathanagul K, Katawatin P, Susantitaphong P, Trakarnvanich T, Kanjanabuch T, Avihingsanon Y, Tungsanga K, Eiam-Ong S. The need for robust validation for MDRD-based glomerular filtration rate estimation in various CKD populations. Nephrol Dial Transplant 2011; 26: 2780-5. 
63 Feng JF, Qiu L, Zhang L, Li XM, Yang YW, Zeng P, Guo XZ, Qin Y, Liu HC, Han XM, Li YP, Xu W, Sun SY, Wang LQ, Quan $\mathrm{H}$, Xia LJ, Hu HZ, Zhong FC, Duan R. Multicenter study of creatinine- and/or cystatin C-based equations for estimation of glomerular filtration rates in chinese patients with chronic kidney disease. PLoS ONE 2013; 8: e57240.

64 Robles NR, Mena C, Cidoncha J. Estimated glomerular filtration rate from serum cystatin C: significant differences among several equations results. Ren Fail 2012; 34: 871-5.

65 Hojs R, Bevc S, Ekart R, Gorenjak M, Puklavec L. Serum cystatin C-based formulas for prediction of glomerular filtration rate in patients with chronic kidney disease. Nephron Clin Pract 2010; 114: c118-26.

66 Masson I, Maillard N, Tack I, Thibaudin L, Dubourg L, Delanaye P, Cavalier E, Bonneau C, Kamar N, Morelon E, Moranne O, Alamartine E, Mariat C. GFR estimation using standardized cystatin $C$ in kidney transplant recipients. Am J Kidney Dis 2013; 61: 279-84.

67 Earley A, Miskulin D, Lamb EJ, Levey AS, Uhlig K. Estimating equations for glomerular filtration rate in the era of creatinine standardization: a systematic review. Ann Intern Med 2012; 156: 785-95, W-270, W-71, W-72, W-73, W-74, W-75, W-76, W-77, W-78.

68 Hillege HL, Fidler V, Diercks GF, van Gilst WH, de Zeeuw D, van Veldhuisen DJ, Gans RO, Janssen WM, Grobbee DE, de Jong PE. Urinary albumin excretion predicts cardiovascular and noncardiovascular mortality in general population. Circulation 2002; 106: 1777-82.

69 Viswanathan G, Upadhyay A. Assessment of proteinuria. Adv Chronic Kidney Dis 2011; 18: 243-8.

70 Abbate M, Zoja C, Remuzzi G. How does proteinuria cause progressive renal damage? JASN 2006; 17: 2974-84.

71 Remuzzi G, Benigni A, Remuzzi A. Mechanisms of progression and regression of renal lesions of chronic nephropathies and diabetes. J Clin Invest 2006; 116: 288-96.

72 Ibsen H, Olsen MH, Wachtell K, Borch-Johnsen K, Lindholm $\mathrm{LH}$, Mogensen CE. Reduction in albuminuria translates to reduction in cardiovascular events in hypertensive patients with left ventricular hypertrophy and diabetes. J Nephrol 2008; 21: 566-9.

73 Price CP, Newall RG, Boyd JC. Use of protein:creatinine ratio measurements on random urine samples for prediction of significant proteinuria: a systematic review. Clin Chem 2005; 51: 1577-86.

74 Ginsberg JM, Chang BS, Matarese RA, Garella S. Use of single voided urine samples to estimate quantitative proteinuria. N Engl J Med 1983; 309: 1543-6.

75 Zelmanovitz T, Gross JL, Oliveira JR, Paggi A, Tatsch M, Azevedo MJ. The receiver operating characteristics curve in the evaluation of a random urine specimen as a screening test for diabetic nephropathy. Diabetes Care 1997; 20: 516-9.

76 Rodby RA, Rohde RD, Sharon Z, Pohl MA, Bain RP, Lewis EJ. The urine protein to creatinine ratio as a predictor of 24-hour urine protein excretion in type 1 diabetic patients with nephropathy. The Collaborative Study Group. Am J Kidney Dis 1995; 26: 904-9.

77 Ruggenenti P, Gaspari F, Perna A, Remuzzi G. Cross sectional longitudinal study of spot morning urine protein:creatinine ratio, 24 hour urine protein excretion rate, glomerular filtration rate, and end stage renal failure in chronic renal disease in patients without diabetes. BMJ 1998; 316: 504-9.

78 Guy M, Borzomato JK, Newall RG, Kalra PA, Price CP. Protein and albumin-to-creatinine ratios in random urines accurately predict $24 \mathrm{~h}$ protein and albumin loss in patients with kidney disease. Ann Clin Biochem 2009; 46: 468-76.

79 Methven S, MacGregor MS, Traynor JP, O'Reilly DS, Deighan CJ. Assessing proteinuria in chronic kidney disease: protein-creatinine ratio versus albumin-creatinine ratio. Nephrol Dial Transplant 2010; 25: 2991-6.

80 Lambers Heerspink HJ, Gansevoort RT, Brenner BM, Cooper $\mathrm{ME}$, Parving $\mathrm{HH}$, Shahinfar S, de Zeeuw D. Comparison of different measures of urinary protein excretion for prediction of renal events. JASN 2010; 21: 1355-60.

81 Lamb EJ, MacKenzie F, Stevens PE. How should proteinuria be detected and measured? Ann Clin Biochem 2009; 46: 205-17.

82 National Institute for Health and Clinical Excellence (NICE). Chronic kidney disease. [online]. Available at http://www.nice.org.uk/cg73 (last accessed 25 July 2013).

83 Scottish Intercollegiate Guidelines Network (SIGN). Diagnosis and management of chronic kidney disease. [online]. Available at http://www.sign.ac.uk/guidelines/ fulltext/103/ (last accessed 25 July 2013).

84 Levey AS, Cattran D, Friedman A, Miller WG, Sedor J, Tuttle K, Kasiske B, Hostetter T. Proteinuria as a surrogate outcome in CKD: report of a scientific workshop sponsored by the National Kidney Foundation and the US Food and Drug Administration. Am J Kidney Dis 2009; 54: 205-26.

85 Towler JD, Dhaun N, Macdougall M, Melville V, Goddard J, Webb DJ. What is the best method of proteinuria measurement in clinical trials of endothelin receptor antagonists? Life Sci 2012; 91: 733-8.

86 Lea J, Greene T, Hebert L, Lipkowitz M, Massry S, Middleton J, Rostand SG, Miller E, Smith W, Bakris GL. The relationship between magnitude of proteinuria reduction and risk of end-stage renal disease: results of the African American study of kidney disease and hypertension. Arch Intern Med 2005; 165: 947-53.

87 Toto RD. Conventional measurement of renal function utilizing serum creatinine, creatinine clearance, inulin and para-aminohippuric acid clearance. Curr Opin Nephrol Hypertens 1995; 4: 505-9; discussion 03-4.

88 Brenna S, Grigoras O, Drukker A, Guignard JP. Pitfalls in measuring inulin and para-amino-hippuric acid clearances. Pediatr Nephrol 1998; 12: 489-91.

89 Vassalotti JA, Stevens LA, Levey AS. Testing for chronic kidney disease: a position statement from the National Kidney Foundation. Am J Kidney Dis 2007; 50: 169-80. 
90 Devarajan P. The use of targeted biomarkers for chronic kidney disease. Adv Chronic Kidney Dis 2010; 17: 469-79.

91 Woods LL. Intrarenal mechanisms of renal reserve. Semin Nephrol 1995; 15: 386-95.

92 Chaudhary K, Phadke G, Nistala R, Weidmeyer CE, McFarlane $\mathrm{SI}$, Whaley-Connell A. The emerging role of biomarkers in diabetic and hypertensive chronic kidney disease. Curr Diab Rep 2010; 10: 37-42.

93 Nickolas TL, Barasch J, Devarajan P. Biomarkers in acute and chronic kidney disease. Curr Opin Nephrol Hypertens 2008; 17: 127-32.

94 Leung KC, Tonelli M, James MT. Chronic kidney disease following acute kidney injury-risk and outcomes. Nat Rev Nephrol 2012; 9: 77-85.

95 Chawla LS, Kimmel PL. Acute kidney injury and chronic kidney disease: an integrated clinical syndrome. Kidney Int 2012; 82: 516-24.

96 Mishra J, Ma Q, Prada A, Mitsnefes M, Zahedi K, Yang J, Barasch J, Devarajan P. Identification of neutrophil gelatinase-associated lipocalin as a novel early urinary biomarker for ischemic renal injury. JASN 2003; 14: 2534-43.

97 Nielsen BS, Borregaard N, Bundgaard JR, Timshel S, Sehested M, Kjeldsen L. Induction of NGAL synthesis in epithelial cells of human colorectal neoplasia and inflammatory bowel diseases. Gut 1996; 38: 414-20.

98 Mori K, Nakao K. Neutrophil gelatinase-associated lipocalin as the real-time indicator of active kidney damage. Kidney Int 2007; 71: 967-70.

99 Mori K, Lee HT, Rapoport D, Drexler IR, Foster K, Yang J, Schmidt-Ott KM, Chen X, Li JY, Weiss S, Mishra J, Cheema FH, Markowitz G, Suganami T, Sawai K, Mukoyama M, Kunis C, D'Agati V, Devarajan P, Barasch J. Endocytic delivery of lipocalin-siderophore-iron complex rescues the kidney from ischemia-reperfusion injury. J Clin Invest 2005; 115: 610-21.

100 Bolignano D, Coppolino G, Lacquaniti A, Nicocia G, Buemi M. Pathological and prognostic value of urinary neutrophil gelatinase-associated lipocalin in macroproteinuric patients with worsening renal function. Kidney Blood Press Res 2008; 31: 274-9.

101 Bolignano D, Lacquaniti A, Coppolino G, Donato V, Campo S, Fazio MR, Nicocia G, Buemi M. Neutrophil gelatinase-associated lipocalin (NGAL) and progression of chronic kidney disease. CJASN 2009; 4: 337-44.

102 Mitsnefes MM, Kathman TS, Mishra J, Kartal J, Khoury PR, Nickolas TL, Barasch J, Devarajan P. Serum neutrophil gelatinase-associated lipocalin as a marker of renal function in children with chronic kidney disease. Pediatr Nephrol 2007; 22: 101-8.

103 Kasahara M, Mori K, Satoh N, Kuwabara T, Yokoi H, Shimatsu A, Sugawara A, Mukoyama M, Nakao K. Reduction in urinary excretion of neutrophil gelatinase-associated lipocalin by angiotensin receptor blockers in hypertensive patients. Nephrol Dial Transplant 2009; 24: 2608-9; author reply 09-10.
104 Kuwabara T, Mori K, Mukoyama M, Kasahara M, Yokoi H, Saito Y, Yoshioka T, Ogawa Y, Imamaki H, Kusakabe T, Ebihara K, Omata M, Satoh N, Sugawara A, Barasch J, Nakao K. Urinary neutrophil gelatinase-associated lipocalin levels reflect damage to glomeruli, proximal tubules, and distal nephrons. Kidney Int 2009; 75: 285-94.

105 Devarajan P. Neutrophil gelatinase-associated lipocalin: new paths for an old shuttle. Cancer Ther 2007; 5: 463-70.

106 Devarajan P. The promise of biomarkers for personalized renal cancer care. Kidney Int 2010; 77: 755-7.

107 Vaidya VS, Ferguson MA, Bonventre JV. Biomarkers of acute kidney injury. Annu Rev Pharmacol Toxicol 2008; 48: 463-93.

108 Ichimura T, Brooks CR, Bonventre JV. Kim-1/Tim-1 and immune cells: shifting sands. Kidney Int 2012; 81:809-11.

109 Han WK, Bailly V, Abichandani R, Thadhani R, Bonventre JV. Kidney Injury Molecule-1 (KIM-1): a novel biomarker for human renal proximal tubule injury. Kidney Int 2002; 62: 237-44.

110 Zhang Z, Humphreys BD, Bonventre JV. Shedding of the urinary biomarker kidney injury molecule-1 (KIM-1) is regulated by MAP kinases and juxtamembrane region. JASN 2007; 18: 2704-14.

111 Liangos O, Perianayagam MC, Vaidya VS, Han WK, Wald R, Tighiouart H, MacKinnon RW, Li L, Balakrishnan VS, Pereira BJ, Bonventre JV, Urinary JBL.

$\mathrm{N}$-acetyl-beta-(D)-glucosaminidase activity and kidney injury molecule-1 level are associated with adverse outcomes in acute renal failure. JASN 2007; 18: 904-12.

112 Vaidya VS, Ford GM, Waikar SS, Wang Y, Clement MB, Ramirez V, Glaab WE, Troth SP, Sistare FD, Prozialeck WC, Edwards JR, Bobadilla NA, Mefferd SC, Bonventre JV. A rapid urine test for early detection of kidney injury. Kidney Int 2009; 76: 108-14.

113 van Timmeren MM, van den Heuvel MC, Bailly V, Bakker SJ, van Goor $\mathrm{H}$, Stegeman CA. Tubular kidney injury molecule-1 (KIM-1) in human renal disease. J Pathol 2007; 212: 209-17.

114 van Timmeren MM, Vaidya VS, van Ree RM, Oterdoom LH, de Vries AP, Gans RO, van Goor H, Stegeman CA, Bonventre JV, Bakker SJ. High urinary excretion of kidney injury molecule- 1 is an independent predictor of graft loss in renal transplant recipients. Transplantation 2007; 84: 1625-30.

115 Waanders F, Vaidya VS, van Goor $H$, Leuvenink H, Damman K, Hamming I, Bonventre JV, Vogt L, Navis G. Effect of renin-angiotensin-aldosterone system inhibition, dietary sodium restriction, and/or diuretics on urinary kidney injury molecule 1 excretion in nondiabetic proteinuric kidney disease: a post hoc analysis of a randomized controlled trial. Am J Kidney Dis 2009; 53: 16-25.

116 Conway BR, Manoharan D, Manoharan D, Jenks S, Dear JW, McLachlan S, Strachan MW, Price JF. Measuring urinary tubular biomarkers in type 2 diabetes does not add prognostic value beyond established risk factors. Kidney Int 2012; 82: 812-8. 
117 Portilla D, Dent C, Sugaya T, Nagothu KK, Kundi I, Moore P, Noiri E, Devarajan P. Liver fatty acid-binding protein as a biomarker of acute kidney injury after cardiac surgery. Kidney Int 2008; 73: 465-72.

118 Kamijo A, Sugaya T, Hikawa A, Yamanouchi M, Hirata Y, Ishimitsu T, Numabe A, Takagi M, Hayakawa H, Tabei F, Sugimoto T, Mise N, Omata M, Kimura K. Urinary liver-type fatty acid binding protein as a useful biomarker in chronic kidney disease. Mol Cell Biochem 2006; 284: 175-82.

119 Kielstein JT, Zoccali C. Asymmetric dimethylarginine: a novel marker of risk and a potential target for therapy in chronic kidney disease. Curr Opin Nephrol Hypertens 2008; 17:609-15.

120 Sharma M, Zhou Z, Miura H, Papapetropoulos A, McCarthy ET, Sharma R, Savin VJ, Lianos EA. ADMA injures the glomerular filtration barrier: role of nitric oxide and superoxide. American journal of physiology. Ren Physiol 2009; 296: F1386-95.

121 Hewitt SM, Dear J, Star RA. Discovery of protein biomarkers for renal diseases. JASN 2004; 15: 1677-89.

122 Final Conclusions on the Pilot Joint EMEA/FDA VXDS Experience on Qualification of Nephrotoxicity Biomarkers. London: European Medicines Agency, 2009. [online] Available at: http://www.ema.europa.eu/docs/en_GB/ document_library/Regulatory_and_procedural_guideline/ 2009/10/WC500004205.pdf (last accessed 29 July 2013).

123 Nangaku M. Chronic hypoxia and tubulointerstitial injury: a final common pathway to end-stage renal failure. JASN 2006; 17: 17-25.

124 Inoue T, Kozawa E, Okada H, Inukai K, Watanabe S, Kikuta T, Watanabe Y, Takenaka T, Katayama S, Tanaka J, Suzuki H.
Noninvasive evaluation of kidney hypoxia and fibrosis using magnetic resonance imaging. JASN 2011; 22: 1429-34.

125 Heyman SN, Khamaisi M, Rosen S, Rosenberger C. Renal parenchymal hypoxia, hypoxia response and the progression of chronic kidney disease. Am J Nephrol 2008; 28: 998-1006.

126 Penfield JG, Reilly RF. Gadolinium and nephrogenic systemic fibrosis: have we overreacted? Semin Dial 2011; 24: 480-6.

127 Thoeny HC, De Keyzer F, Oyen RH, Peeters RR. Diffusion-weighted MR imaging of kidneys in healthy volunteers and patients with parenchymal diseases: initial experience. Radiology 2005; 235: 911-7.

128 Togao O, Doi S, Kuro-o M, Masaki T, Yorioka N, Takahashi M. Assessment of renal fibrosis with diffusion-weighted MR imaging: study with murine model of unilateral ureteral obstruction. Radiology 2010; 255: 772-80.

129 Xu X, Fang W, Ling H, Chai W, Chen K. Diffusion-weighted MR imaging of kidneys in patients with chronic kidney disease: initial study. Eur Radiol 2010; 20: 978-83.

130 Schachinger $\mathrm{H}$, Klarhofer M, Linder L, Drewe J, Scheffler K. Angiotensin II decreases the renal MRI blood oxygenation level-dependent signal. Hypertension 2006; 47: 1062-6.

131 Michaely HJ, Metzger L, Haneder S, Hansmann J, Schoenberg SO, Attenberger UI. Renal BOLD-MRI does not reflect renal function in chronic kidney disease. Kidney Int 2012; 81: 684-9. 